\title{
PREDICTORS OF OPERATIVE RISK FOR CORONARY BYPASS OPERATIONS IN PATIENTS WITH LEFT VENTRICULAR DYSFUNCTION
}

Terrence M. Yau, MD, MSc

Paul W. M. Fedak, MD

Richard D. Weisel, MD

Carolyn Teng, MSc

Joan Ivanov, MSc
Objectives: The prevalence of ventricular dysfunction in patients undergoing coronary operations, as well as the prevalence of other risk factors in these patients, has been increasing. We identified the predictors of mortality and morbidity in patients with ventricular dysfunction to permit more accurate evaluation of risk and to direct future strategies to improve outcomes. Methods: Demographic, intraoperative, and outcome data were collected prospectively on $\mathbf{2 0 , 6 1 4}$ patients undergoing isolated coronary operations at our institution from 1982-1997. Multivariable regression analyses were used to identify the independent predictors of mortality and low-output syndrome. Results: Moderate ventricular dysfunction (ejection fraction, 20\%-40\%) was noted in 4107 (19.9\%) patients, and severe dysfunction (ejection fraction, <20\%) was noted in $680(3.3 \%)$ patients. Patients with worse ventricular function had an increasing prevalence of other risk factors with time. Mortality decreased between the 1982-1986 and 1987-1991 cohorts but did not decrease further. Low-output syndrome was less common in the 19921997 cohort than in previous years. The predictors of mortality were ventricular dysfunction, age, reoperation, year of operation, urgency, female sex, and left main stenosis. Low-output syndrome was predicted by ventricular dysfunction, reoperation, year of operation, female sex, urgency, extensive coronary disease, age, left main stenosis, and symptom class. Conclusions: Despite the increasing prevalence and risk profile of patients with ventricular dysfunction, mortality rates and incidence of low-output syndrome declined with time. Patients with severe dysfunction were at greatest risk when facing reoperation or urgent operation. Earlier intervention and more aggressive preoperative optimization may improve outcomes in these high-risk patients. (J Thorac Cardiovasc Surg 1999;118:1006-13)
0 perative morbidity and mortality rates during coronary bypass surgery have decreased substantially during the past 2 decades. The overall mortality rate of patients undergoing coronary bypass operations at our institution fell from $4.0 \%$ in 1982 to $2.2 \%$ in 1997.

\footnotetext{
From the Division of Cardiovascular Surgery, Toronto General Hospital, Department of Surgery, University of Toronto, Toronto, Ontario, Canada.

Received for publication Jan 25, 1999; revisions requested March 15, 1999; revisions received May 25, 1999; accepted for publication Aug 11, 1999.

Address for reprints: Terrence M. Yau, MD, MSc, 13 EN-239, Toronto General Hospital, 200 Elizabeth Street, Toronto, Ontario M5G 2C4, Canada.

Copyright (C) 1999 by Mosby, Inc.

$0022-5223 / 99 \$ 8.00+0 \quad \mathbf{1 2 / 1 / 1 0 2 0 8 1}$
}

However, certain high-risk subgroups of patients remain at elevated risk of complications and death despite progressive advances in perioperative care and myocardial protection. ${ }^{1}$ We have previously identified left ventricular (LV) dysfunction as one of the most significant independent predictors of operative mortality ${ }^{2}$ and low-output syndrome ${ }^{3}$ during coronary bypass operations. We have noted both an increasing prevalence of patients presenting with preoperative LV dysfunction and an increasing profile of comorbidity and other risk factors within this subgroup. We therefore attempted to identify the independent predictors of operative mortality and morbidity in patients with moderate or severe LV dysfunction to permit more accurate evaluation of risk in these patients and to direct the development of novel strategies to improve outcomes. 
Table I. Number of patients by year of operation and LVEF

\begin{tabular}{lcccr}
\hline & $1982-1986$ & $1987-1991$ & $1992-1997$ & All years \\
\hline LVEF $>40 \%$ & $4582(78.5 \%)$ & $4554(76.8 \%)$ & $6465(75.0 \%)$ & 15,601 \\
LVEF 20\%-40\% & $1072(18.4 \%)$ & $1162(19.6 \%)$ & $1873(21.7 \%)$ & 4107 \\
LVEF < 20\% & $186(3.2 \%)$ & $216(3.6 \%)$ & $278(3.2 \%)$ & 680 \\
All patients & 5840 & 5932 & 8616 & 20,388 \\
\hline
\end{tabular}

Table II. Demographic details of 20,388 patients by LVEF

\begin{tabular}{|c|c|c|c|c|}
\hline & $L V E F>40 \%$ & LVEF $20 \%-40 \%$ & $L V E F<20 \%$ & $\mathrm{P}$ value \\
\hline Age (y) & $60.3 \pm 9.7$ & $61.2 \pm 9.7$ & $60.2 \pm 9.6$ & $<.0001$ \\
\hline Sex ( $\%$ male $)$ & 78.9 & 83.8 & 86.2 & $<.0001$ \\
\hline $\begin{array}{l}\text { NYHA class } \\
(\% \mathrm{I} / \mathrm{II} / \mathrm{II} / \mathrm{IV})\end{array}$ & 2.6/17.7/39.8/39.9 & 2.3/11.5/36.7/49.5 & $1.6 / 8.4 / 31.5 / 58.5$ & $<.0001$ \\
\hline $\begin{array}{l}\text { No. of diseased vessels } \\
(\% 1 / 2 / 3)\end{array}$ & $6.4 / 23.5 / 70.1$ & 2.1/17.6/80.3 & $2.2 / 16.7 / 81.1$ & $<.0001$ \\
\hline Left main stenosis (\%) & 16.4 & 15.8 & 20.4 & .01 \\
\hline Reoperative surgery (\%) & 5.2 & 8.7 & 7.5 & $<.0001$ \\
\hline $\begin{array}{l}\text { Preoperative MI } \\
<30 \text { days }(\%)\end{array}$ & 19.2 & 33.2 & 35.9 & $<.0001$ \\
\hline Preoperative IABP (\%) & 2.7 & 4.6 & 8.1 & $<.0001$ \\
\hline $\begin{array}{l}\text { Urgency (\% elective/ } \\
\text { urgent/emergency) }\end{array}$ & $69.1 / 16.9 / 14.0$ & $62.9 / 19.7 / 17.4$ & $60.4 / 17.4 / 22.2$ & $<.0001$ \\
\hline
\end{tabular}

MI, Myocardial infarction.

Table III. Intraoperative details of 20,388 patients by LVEF

\begin{tabular}{|c|c|c|c|c|}
\hline & $L V E F>40 \%$ & LVEF $20 \%-40 \%$ & $L V E F<20 \%$ & $\mathrm{P}$ value \\
\hline $\begin{array}{l}\text { No. of grafts } \\
(\% 1 / 2 / 3 / 4)\end{array}$ & $3.1 / 13.1 / 35.7 / 37.7$ & $1.4 / 10.1 / 35.3 / 42.5$ & 2.4/11.3/34.6/43.4 & \\
\hline No. of grafts $(\% 5 / 6 / 7)$ & $9.9 / 0.4 / 0.01$ & $9.9 / 0.7 / 0.07$ & $8.2 / 0.2 / 0.0$ & $<.0001$ \\
\hline LITA (\% 1982-1997) & 69.3 & 65.1 & 54.0 & $<.0001$ \\
\hline $\begin{array}{l}\text { LITA (\% 1992-1997, } \\
8614 \text { patients) }\end{array}$ & 89.1 & 83.2 & 73.0 & $<.0001$ \\
\hline CPB time (min) & $86.3 \pm 30.7$ & $91.7 \pm 28.5$ & $99.6 \pm 35.2$ & $<.0001$ \\
\hline $\begin{array}{l}\text { Crossclamp time } \\
(\mathrm{min})\end{array}$ & $56.9 \pm 20.3$ & $59.7 \pm 18.6$ & $60.2 \pm 19.4$ & $<.0001$ \\
\hline
\end{tabular}

$C P B$, Cardiopulmonary bypass.

\section{Methods}

Data source. Demographic, anatomic, intraoperative, and in-hospital outcome data were collected prospectively and entered into a computerized database on all patients undergoing cardiac surgery at our institution (The Toronto Hospital, formerly the Toronto General and Toronto Western Hospitals). From this database, the records of all patients undergoing isolated coronary artery bypass grafting between January 1, 1982, and December 31, 1997, were retrieved for analysis.

Core fields collected in our database since its inception in 1982 included age, sex, LV grade (based on LV ejection fraction [LVEF]: grade 1, LVEF >60\%; grade 2, LVEF $40 \%$ $60 \%$; grade 3, LVEF 20\%-39\%; and grade 4, LVEF < 20\%), previous coronary artery bypass operations, urgency of the operation (elective; semiurgent, indicating surgery during the same admission as cardiac catheterization or a cardiac event; or emergency, indicating surgery within 12 hours of cardiac catheterization or a cardiac event), number of coronary arteries with significant stenoses, left main stenosis of greater than $50 \%$, severity of angina, and New York Heart Association (NYHA) functional class. LVEF was determined semiquantitatively by contrast ventriculography. Echocardiography and nuclear ventriculography were carried out in a minority of patients, and when these additional data were available, the greatest value for LVEF obtained was used for subsequent analysis. In the minority of patients in whom these estimates differed, this was generally caused by performance of one study within 1 to 3 days after a myocardial infarction, resulting in overestimation of LV dysfunction, with a subsequent 


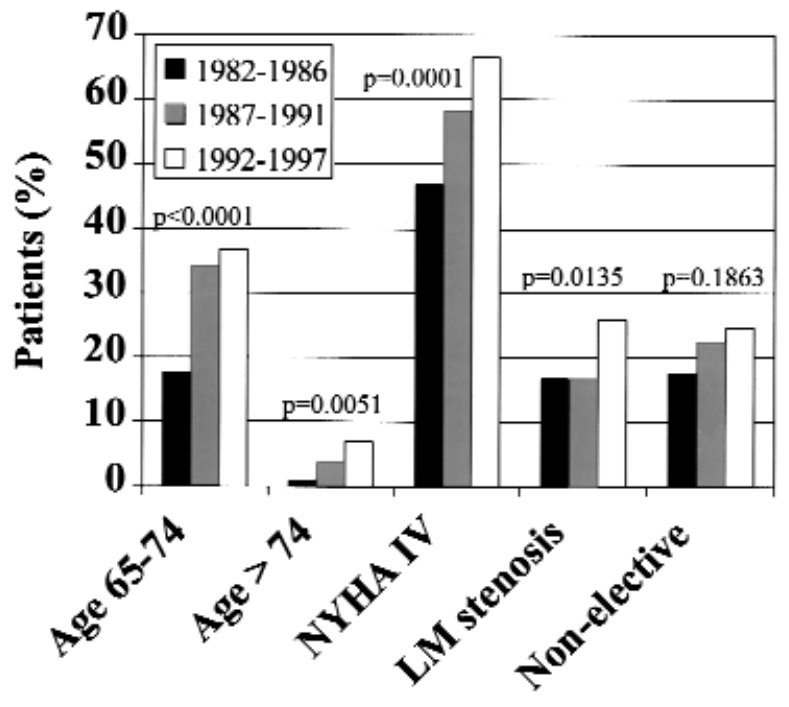

Fig 1. The prevalence of operative risk factors in 20,614 patients undergoing isolated coronary artery bypass grafting over 3 time periods (1982-1986, 1987-1991, and 1992-1997). Patient age and symptom class increased significantly with more recent year of operation, as did the prevalence of left main coronary artery stenosis and the requirement for an urgent or emergency operation. LM, Left main; Non-elective, Requiring urgent or emergency surgery.

study showing partial recovery of contractility. In these cases the later study (always resulting in a higher estimated LVEF) was used for analysis. Core data were complete on 20,388 $(98.9 \%)$ of 20,614 patients.

Analysis. Data were collected and managed in dBASE IV datasets and analyzed with SAS and BMDP/DYN LR statistical analysis software (SAS Institute, Inc, Cary, NC; BMDP Software, Los Angeles, Calif). Univariate analysis of categorical data was carried out by using $\chi^{2}$ analysis or the Fisher exact test. Univariate analysis of continuous variables was carried out by using the Student $t$ test. Variables that had a univariate $P$ value of less than .25 or those of known biologic importance but failing to meet the critical $\alpha$ level were submitted for consideration to logistic regression analysis by using stepwise selection. Multivariable logistic regression methods were used to calculate risk-adjusted mortality rates and factor-adjusted odds ratios. Model discrimination was evaluated by the area under the receiver-operator characteristic curve, and calibration was assessed with the HosmerLemeshow goodness-of-fit statistic. For goodness-of-fit, the null hypothesis is that the model fits the data. Therefore a nonsignificant $P$ value is desired because $P$ values of less than .05 would indicate a poor fit between predicted and observed results.

Evaluation of temporal trends. Rather than constructing a complex model to assess the temporal trends in prevalence, risk profiles, and outcomes, we used a simpler approach based on risk stratification and contingency tables. To examine the effect of time on patient risk profiles and outcomes, patients were divided into 3 groups based on the year of operation (1982-1986, 1987-1991, and 1992-1997). Contingency table analysis was then used to examine changes in the prevalence of LV dysfunction, risk factors, and operative mortality over time and among the 3 risk groups.

\section{Results}

\section{Demographics}

Prevalence of $L V$ dysfunction. A total of 15,601 patients had no or only mild LV dysfunction (LVEF > $40 \%$ for $75.7 \%$ of all patients), whereas 4107 (19.9\%) patients had moderate dysfunction (LVEF $20 \%-40 \%$ ), and $680(3.3 \%)$ patients had severe dysfunction (LVEF $<20 \%$ ). The number of patients, categorized by LVEF and by year of operation, is shown in Table I. The proportion of patients presenting with an LVEF of $20 \%$ to $40 \%$ increased from $18.4 \%$ in $1982-1986$ to $21.7 \%$ in 1992-1997, but the proportion of patients with an LVEF of less than $20 \%$ remained constant.

Additional risk factors in patients with $L V$ dysfunction. Demographic details, grouped by degree of LV dysfunction, are listed in Table II. Patients with worse LV function were more likely to be male and to have more extensive coronary disease or left main coronary artery stenosis. The acuity of patients with worse LV function was greater, with higher NYHA symptom class and a greater likelihood of requiring an urgent or emergency operation. The prevalence of preoperative intra-aortic balloon pump (IABP) support was greatest in patients with severe ventricular dysfunction. These patients were therefore more likely to require an urgent or emergency operation.

Increasing risk profile of patients with $L V$ dysfunction. In more recent years, patients with LVEF of less than $20 \%$ were older and more symptomatic (Fig 1). They were also more likely to have left main stenosis $(P=.01)$ and to require an urgent or emergency operation, although the trend to more urgent operation did not reach statistical significance.

Patients with an LVEF of $20 \%$ to $40 \%$ demonstrated a similar statistically significant increase in patient age, symptom class, left main stenosis, and need for urgent or emergency operation. In addition, in this subgroup there was also an increasing number of female patients $(1982-1986,13.9 \%$; 1987-1991, 15.7\%; and 1992$1997,17.8 \% ; P=.02)$ and a greater prevalence of reoperative surgery $(1982-1986,6.2 \%$; 1987-1991, 9.6\%; and 1992-1997, 9.6\%; $P=.003$ ).

Intraoperative data. Intraoperative details, grouped by degree of LV dysfunction, are listed in Table III. 


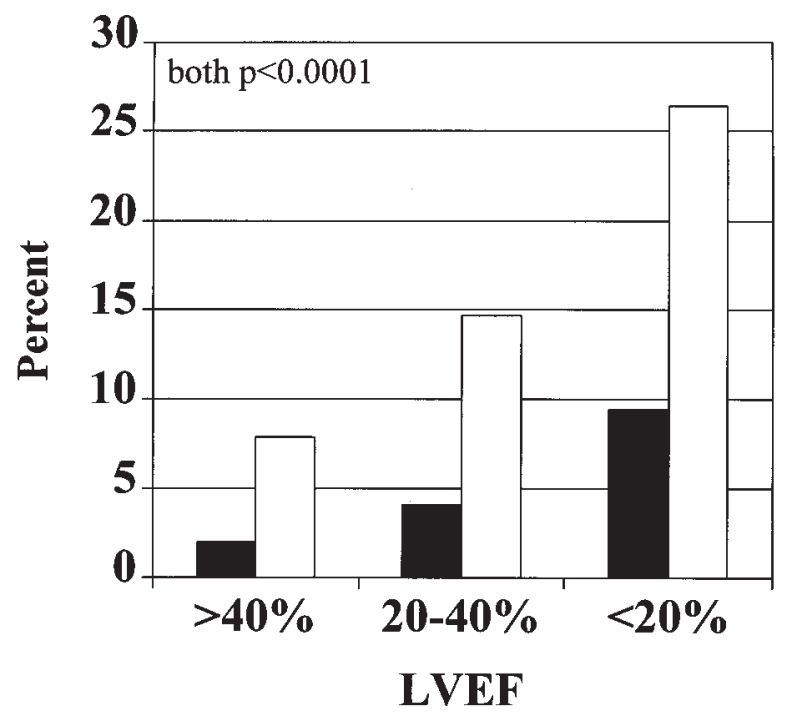

$\square$ Mortality $\square$ Low Output Syndrome

Fig 2. Operative mortality rate and incidence of postoperative low-output syndrome, as determined by preoperative LVEF. Mortality rate was low in patients with no or minimal ventricular dysfunction but doubled when LVEF was $20 \%$ to $40 \%$ and was more than quadrupled in patients with LVEFs of less than $20 \%$. Low-output syndrome was uncommon in patients with no or minimal ventricular dysfunction but was twice as common when LVEFs were $20 \%$ to $40 \%$ and 3 times as common in patients with LVEFs of less than $20 \%$.

Although overall use of the left internal thoracic artery (LITA) increased with year of operation (1982-1986, $36.0 \%$; 1987-1991, 70.6\%; and 1992-1997, 87.3\%; $P<$ .0001 ), patients with worse LV function were less likely to receive an internal thoracic artery (ITA) graft in any year.

Most patients received 3 or 4 bypass grafts. The duration of cardiopulmonary bypass was greater in patients with worse ventricular function (Table III). The duration of aortic crossclamping was similar between groups, ranging from approximately 57 to 60 minutes.

In earlier years, systemic perfusion was carried out at moderate hypothermia $\left(1982-1986: 25^{\circ} \mathrm{C}-29^{\circ} \mathrm{C}\right.$ for $96 \%$ and $30^{\circ} \mathrm{C}-35^{\circ} \mathrm{C}$ for $4 \%$ of patients) but our routine is now to use only mild hypothermia (1992-1997: $25^{\circ} \mathrm{C}-29^{\circ} \mathrm{C}$ for $9 \%, 30^{\circ} \mathrm{C}-35^{\circ} \mathrm{C}$ for $82 \%$, and $36^{\circ} \mathrm{C}-$ $37^{\circ} \mathrm{C}$ for $9 \%$ of patients; $P<.0001$ vs $\left.1982-1986\right)$. The degree of systemic hypothermia was not different, however, between LVEF groups. Antegrade cold blood cardioplegia was used for myocardial protection in $91 \%$ to $95 \%$ of patients over the 3 time periods; the technique

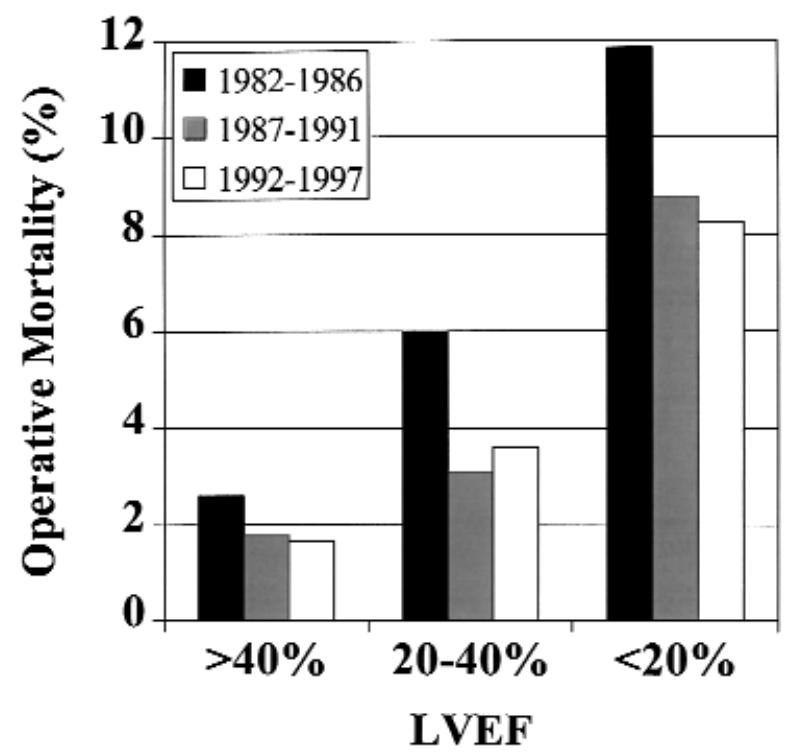

Fig 3. Operative mortality rates, as determined by preoperative LVEF, over 3 time periods (1982-1986, 1987-1991, and 1992-1997). Mortality decreased from the 1982-1986 cohort to the 1987-1991 cohort in all LVEF groups, but the reduction was most marked in patients with LVEFs of less than $40 \%$. No further reduction in mortality rate was noted from the 1987-1991 cohort to the 1992-1997 cohort.

of cardioplegia was not different between LVEF groups.

\section{Outcomes}

Operative mortality rates. The overall operative mortality rate increased with greater LV dysfunction $(P<$ .0001 ; Fig 2). Mortality decreased between the 1982 1986 and 1987-1991 cohorts in all LVEF groups but did not decrease further in the 1992-1997 cohort (Fig 3).

Myocardial infarction. The rate of perioperative myocardial infarction was not different between LVEF groups (LVEF > 40\%, 3.8\%; LVEF 20-40\%, 4.0\%; and LVEF $<20 \%, 4.9 \% ; P=.4)$.

Low-output syndrome. Postoperative low cardiac output syndrome (the requirement for inotropic or IABP support to maintain a cardiac index of greater than 2.0 $\mathrm{L} \cdot \mathrm{min}^{-1} \cdot \mathrm{m}^{-2}$ despite optimization of heart rate, preload, and afterload) was significantly greater in patients with LV dysfunction $(P<.0001$; Fig 2$)$.

The rate of low-output syndrome fell between the 1987-1991 and 1992-1997 cohorts, but even in the latest cohort, low-output syndrome was still 4 times as common in patients with LVEFs of less than $20 \%$ as it was in patients with LVEFs of greater than $40 \%(P<$ .0001; Fig 4).

IABP support. Placement of an IABP preoperatively 


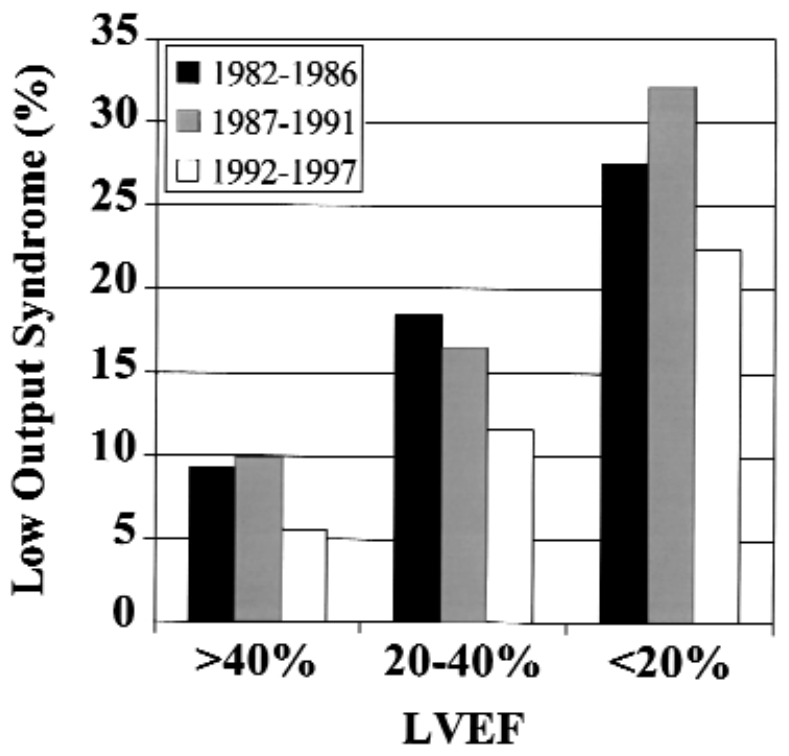

Fig 4. The prevalence of postoperative low-output syndrome, as determined by preoperative LVEF, over 3 time periods (1982-1986, 1987-1991, and 1992-1997). Low-output syndrome decreased with time in all LVEF groups but only from the 1987-1991 cohort to the 1992-1997 cohort.

Table IV. Multivariable predictors of operative mortality in all 20,614 patients

\begin{tabular}{lrcc}
\hline Variable & $\begin{array}{c}\text { Regression } \\
\text { coefficient }\end{array}$ & OR & $95 \%$ CI \\
\hline Constant & $-0.9659 \pm 0.911$ & & \\
Age & $0.0464 \pm 0.005$ & 1.048 & $1.037-1.058$ \\
LV grade & $0.5385 \pm 0.051$ & 1.713 & $1.550-1.894$ \\
NYHA class & $0.3301 \pm 0.078$ & 1.391 & $1.193-1.622$ \\
Reoperative surgery & $1.0538 \pm 0.128$ & 2.869 & $2.234-3.683$ \\
Urgency & $0.4340 \pm 0.074$ & 1.543 & $1.334-1.786$ \\
Year of operation & $-0.0997 \pm 0.010$ & 0.905 & $0.887-0.924$ \\
Female sex & $0.5601 \pm 0.099$ & 1.751 & $1.441-2.127$ \\
Left main stenosis & $0.4737 \pm 0.105$ & 1.606 & $1.309-1.971$ \\
\hline
\end{tabular}

The area under the receiver-operator characteristic curve was 0.754 . The Hosmer-Lemeshow goodness-of-fit $P$ value was .375 .

LV grade: 1 , LVEF > 60\%; 2, LVEF 40\%-60\%; 3, LVEF 20\%-40\%; 4, LVEF < 20\%. Urgency: 0, Elective; 1, same hospitalization; 2, within 12 hours of a cardiac catheterization or cardiac event (eg, myocardial infarction and unstable angina). Year of operation: 1982-1997. OR, Odds ratio; CI, confidence interval.

in the coronary care unit for refractory angina or cardiogenic shock was required more often in patients with LV dysfunction (LVEF > 40\%, 2.7\%; LVEF 20\%40\%, 4.6\%; and LVEF < 20\%, 8.1\%; $P<.0001)$. Surgeons were also more likely to place an IABP prophylactically in the operating room before commencement of the surgical procedure to provide perioperative support in patients with poor ventricular function
Table V. Multivariable predictors of low-output syndrome in all 20,614 patients

\begin{tabular}{lccc}
\hline Variable & $\begin{array}{c}\text { Regression } \\
\text { coefficient }\end{array}$ & OR & 95\% CI \\
\hline Constant & $0.7957 \pm 0.511$ & & \\
Age & $0.0246 \pm 0.003$ & 1.025 & $1.109-1.031$ \\
LV grade & $0.4469 \pm 0.030$ & 1.563 & $1.475-1.657$ \\
NYHA class & $0.0949 \pm 0.040$ & 1.100 & $1.017-1.189$ \\
Reoperative surgery & $1.1951 \pm 0.078$ & 3.304 & $2.838-3.846$ \\
Urgency & $0.4214 \pm 0.046$ & 1.524 & $1.393-1.668$ \\
Year of operation & $-0.0884 \pm 0.006$ & 0.915 & $0.905-0.926$ \\
Female sex & $0.7325 \pm 0.058$ & 2.080 & $1.858-2.330$ \\
Left main stenosis & $0.2311 \pm 0.064$ & 1.260 & $1.111-1.429$ \\
Extent of coronary & $0.3394 \pm 0.051$ & 1.404 & $1.270-1.552$ \\
$\quad$ artery disease & & & \\
\hline
\end{tabular}

The area under the receiver-operator characteristic curve was 0.719 . The Hosmer-Lemeshow goodness-of-fit $P$ value was .673.

$L V$ grade: 1 , LVEF > 60\%; 2, LVEF 40\%-60\%; 3, LVEF 20\%-40\%; 4, LVEF < 20\%. Urgency: 0, Elective; 1, same hospitalization; 2, within 12 hours of a cardiac catheterization or cardiac event (eg, myocardial infarction and unstable angina). Year of operation: 1982-1997. Extent of coronary artery disease: Number of diseased vessels $(0,1,2$, or 3$)$. $O R$, Odds ratio; $C I$, confidence interval.

(LVEF > 40\%, 0.9\%; LVEF 20\%-40\%, 1.7\%; and LVEF $<20 \%, 9.3 \% ; P<.0001)$. Postoperative placement of an IABP (whether in the operating room at the conclusion of the surgical procedure or in the intensive care unit) for hemodynamic support was also related to the degree of ventricular dysfunction (LVEF $>40 \%$, $3.8 \%$; LVEF 20\%-40\%, 8.5\%; and LVEF < 20\%, $13.8 \% ; P<.0001)$.

Other outcomes. Perioperative cerebrovascular accidents were more common with greater LV impairment (LVEF > 40\%, 1.4\%; LVEF 20\%-40\%, 2.5\%; and LVEF $<20 \%, 3.8 \% ; P<.0001)$. Deep sternal infections were also more common in patients with greater LV dysfunction (LVEF > 40\%, 1.9\%; LVEF 20\%-40\%, $3.1 \%$; and LVEF $<20 \%, 3.2 \% ; P<.0001)$. In general, deep sternal infection rates have fallen with time; in 1997 , only $0.7 \%$ of patients undergoing coronary artery bypass grafting developed sternal osteomyelitis.

Predictors of operative mortality and low-output syndrome

Independent predictors of operative mortality by $L V E F$. Preoperative patient variables that were univariate predictors of operative mortality and variables of known biologic importance not meeting the critical $\alpha$ level were entered into a multivariable regression model for the entire patient cohort. The independent predictors of mortality were greater LV dysfunction, increased age, reoperative surgery, earlier year of operation, urgent surgery, female sex, and left main stenosis (Table IV). 
In patients with LVEFs of $20 \%$ to $40 \%$, the independent predictors of mortality were reoperative surgery $\left(\chi^{2}, 38.09 ; P<.0001\right)$, earlier year of operation $\left(\chi^{2}\right.$, 26.81; $P<.0001)$, female sex $\left(\chi^{2}, 17.72 ; P<.0001\right)$, urgent surgery $\left(\chi^{2}, 15.48 ; P=.0004\right)$, and increased age $\left(\chi^{2}, 13.15 ; P=.001\right)$.

For the smallest group of patients, with the greatest LV impairment (LVEF < 20\%), the only significant independent predictors were urgent surgery $\left(\chi^{2}, 16.43\right.$; $P=.0003)$ and reoperative surgery $\left(\chi^{2}, 5.38 ; P=.02\right)$.

Independent predictors of low-output syndrome by $L V E F$. Preoperative patient variables that were predictive of postoperative low cardiac output syndrome in the entire patient cohort are listed in Table V.

In patients with LVEFs of $20 \%$ to $40 \%$, the independent predictors of low-output syndrome were reoperative surgery $\left(\chi^{2}, 87.63 ; P<.0001\right)$, earlier year of operation $\left(\chi^{2}, 55.29 ; P<.0001\right)$, female sex $\left(\chi^{2}, 54.18 ; P<\right.$ $.0001)$, urgent surgery $\left(\chi^{2}, 33.11 ; P<.0001\right)$, more extensive coronary disease $\left(\chi^{2}, 14.18 ; P=.0008\right)$, increased age $\left(\chi^{2}, 11.61 ; P=.003\right)$, and NYHA class $\left(\chi^{2}, 8.34 ; P=.04\right)$.

In patients with LVEFs of less than $20 \%$, the predictors of low-output syndrome were urgent surgery $\left(\chi^{2}\right.$, 16.62; $P=.0002)$, left main stenosis $\left(\chi^{2}, 8.06 ; P=\right.$ $.004)$, earlier year of operation $\left(\chi^{2}, 7.95 ; P=.02\right)$, and reoperative surgery $\left(\chi^{2}, 5.22 ; P=.02\right)$.

\section{Discussion}

In our experience LV dysfunction has been the most significant independent predictor of operative mortality and postoperative low-output syndrome. In the 16-year time span from 1982-1997, we noted an increasing prevalence of moderate-to-severe LV dysfunction in patients referred for coronary artery bypass grafting. This increase may have been due to the widespread application of thrombolysis, increasing the number of patients surviving acute myocardial infarctions to require revascularization, and of angioplasty, which may delay surgical revascularization until coronary atherosclerosis is more extensive and ventricular dysfunction is more severe. The risk profile of patients referred for coronary bypass surgery has increased with time, ${ }^{1}$ and this trend has been particularly marked in patients with preoperative ventricular dysfunction. In the later years of this series, patients with LVEFs of less than $40 \%$ were older, more symptomatic, more likely to have left main stenosis, and more likely to require urgent or reoperative surgery. All of these factors have also been identified as independent predictors of operative mortality, ${ }^{2}$ low-output syndrome, ${ }^{3}$ or both.

The operative mortality rate decreased in all patients between the 1982-1986 and 1987-1991 cohorts, and the decline was most marked in patients with LVEFs of less than $40 \%$. However, no further reduction in the mortality rate was noted from the 1987-1991 cohort to the 1992-1997 cohort. During this most recent decade, incremental improvements in perioperative patient management were offset by the increasing risk profile of patients with LVEFs of less than $40 \%$, resulting in stable overall mortality rates. Estefanous and colleagues ${ }^{4}$ have reported a comparison of 2 cohorts of patients undergoing coronary artery bypass grafting (1986-1988 vs 1993-1994) from the Cleveland Clinic and also noted an increasing risk profile with time. The gross mortality rate was greater in the more recent cohort, but the risk-adjusted mortality rate was unchanged. Smaller single-institution series have reported variable results in patients with moderate-tosevere ventricular dysfunction; Baumgartner and colleagues ${ }^{5}$ reported an overall mortality rate of $8 \%$ in 61 patients with LVEFs of less than $25 \%$ undergoing coronary artery bypass grafting, and Elefieriades and colleagues ${ }^{6}$ had a mortality rate of $5.2 \%$ in 135 patients with LVEFs of less than $30 \%$. Mickleborough and colleagues ${ }^{7}$ reported a mortality rate of only $3.8 \%$ in 79 patients with severe LV dysfunction (mean LVEF $18 \%$ ). These results were attributed in part to careful myocardial temperature mapping with cold cardioplegia to maintain myocardial protection.

Earlier year of operation was an independent predictor of both operative mortality and postoperative lowoutput syndrome in patients with LVEFs of $20 \%$ to $40 \%$. Year of operation did not predict outcomes in patients with LVEFs of less than $20 \%$, but this may have been due to the much smaller number of patients in this group. This time-related improvement may have been due to progressive advances in anesthetic technique, myocardial protection, and postoperative intensive care. Most surgeons at our institution have used intermittent cold antegrade blood cardioplegia as a standard technique of myocardial protection for coronary artery bypass grafting, adding retrograde cardioplegia for specific anatomic indications or for ongoing myocardial ischemia. Tepid $\left(29^{\circ} \mathrm{C}\right)^{8}$ or warm $\left(37^{\circ} \mathrm{C}\right)^{9,10}$ blood cardioplegia was used in a minority of patients and only since 1990, and the effect of cardioplegia temperature on operative outcomes is therefore difficult to determine in this cohort. However, a terminal hot shot of warm blood cardioplegia before crossclamp removal was universally adopted by our surgeons in 1987-1988 after a randomized clinical trial demonstrated improved perioperative myocardial metabolism and function with this technique. ${ }^{11}$ This consistent change 
to our institutional strategy of myocardial protection may have contributed to the overall improvement in results noted with time and particularly to the decrease in the prevalence of low-output syndrome from the 1987-1991 cohort to the 1992-1997 group. However, because the adoption of the hot shot was so directly related to year of operation, it was not possible to separate the effects of these 2 factors in our analyses.

During the 16 years from 1982-1997, overall use of the LITA as a bypass conduit increased markedly, but patients with worse ventricular function were less likely to receive an ITA graft regardless of the year of operation. Although the reason for not using an ITA graft was not recorded in our database, a number of concerns about the short-term limitations of ITA grafts may have made surgeons more likely to use venous conduits in these high-risk patients. These considerations may have included the time required for ITA harvesting in unstable patients, lower initial flow compared with vein grafts, the potential for spasm (particularly in patients likely to receive vasoactive inotropic agents), and the inability to deliver cardioplegic solution down a pedicled arterial graft. In addition, the relative benefit of use of the LITA on late mortality rate, myocardial infarction, and reintervention in the setting of severe ventricular dysfunction has not been well established. The reduced late survival associated with LV dysfunction, advanced age, and significant comorbidity in these patients may offset the survival advantage generally associated with LITA use. Selection bias may account for the lower operative mortality and morbidity rates associated with LITA use in some series. Baumgartner and colleagues ${ }^{5}$ have suggested that the indications for and results of its use in this subgroup of patients have been poorly documented and require further investigation. Despite these concerns, a number of recent studies have reported LITA use in $76 \%$ to $86 \%$ of patients with ventricular dysfunction, with excellent initial results. ${ }^{6,7}$ Other recent series quote its use in as few as $41 \%$ of patients. ${ }^{5}$ Canver and colleagues ${ }^{12}$ reported a diminished survival benefit with use of the LITA conduit in patients with LV dysfunction. Early outcomes were not influenced by its use, and it was not established if use of the LITA in the setting of ventricular compromise was deleterious. Anderson and colleagues ${ }^{13}$ reported use of the LITA in $70 \%$ of patients with ventricular dysfunction presenting with chronic congestive heart failure and reported that its use enhanced late survival. Reports are conflicting, and the magnitude of benefit of the LITA in patients with severely depressed LVEFs remains to be definitively established.
In patients with severe LV impairment (LVEF < $20 \%$ ), the need for urgent surgery or reoperative surgery were independent predictors of both operative mortality and low-output syndrome. Earlier surgical intervention in patients with progressive angina who are known to have significant ventricular dysfunction may reduce overall mortality rates and the prevalence of low-output syndrome because acute myocardial ischemia in patients requiring urgent revascularization increases operative risk. Alternatively, more aggressive intervention to treat ischemia and stabilize the patient preoperatively may also improve outcomes. Dietl and colleagues $^{14}$ reported in a retrospective study that patients with LVEFs of less than $25 \%$ in whom an IABP was placed preoperatively had lower 30-day mortality rates, shorter hospital stays, and lower hospital charges than patients without preoperative IABP support. Christenson and colleagues ${ }^{15}$ reported that preoperative IABP support in high-risk patients undergoing coronary artery bypass grafting, $87 \%$ of whom had LVEFs of less than $40 \%$, resulted in lower operative mortality rates, lower requirements for inotropic drugs, and shorter intensive care unit stays. Although the low but finite complication rate of IABP insertion may make elective placement of balloon pumps undesirable in the majority of patients requiring urgent coronary artery bypass grafting, it may be a reasonable option in patients with severe LV impairment. Cimochowski and colleagues ${ }^{16}$ reported that a combination of liberal use of IABP support in combination with a cocktail of metabolic and mechanical support strategies resulted in a remarkable $1.8 \%$ mortality rate in 111 patients with LVEFs of $10 \%$ to $34 \%$.

In patients with the most severe LV dysfunction, often related to end-stage ischemic cardiomyopathy, cardiac transplantation may be considered. However, because of the continuing shortage of donor organs and the consequences of long-term immunosuppression, high-risk coronary artery bypass grafting may be considered for patients with adequate target vessels and evidence of reversible ischemia on viability studies. We, and other institutions, have used this strategy with reasonable outcomes in this select patient population. ${ }^{7,17}$ The presence of a large reversible thallium defect is associated with a greater likelihood of improvement in LVEF after revascularization. Chan and colleagues ${ }^{18}$ noted that a large reversible thallium defect predicted an improvement of $5 \%$ or more in LVEF after coronary artery bypass grafting, with an adjusted odds ratio of 15 . Even a presentation with symptoms of congestive heart failure alone, without angina, does not necessarily indicate a fixed defect and 
a higher risk of operation. Anderson and colleagues ${ }^{13}$ reported a series of 203 patients with chronic congestive heart failure but no angina and a mean LVEF of $34 \%$ in whom coronary artery bypass grafting was performed with a hospital mortality rate of $6.0 \%$ and a 5year survival of $59 \%$. In these patients transplantation may still be offered if clinical improvement does not occur with revascularization alone.

Our results suggest that although the risk of coronary artery bypass grafting is generally low, patients with significant ventricular dysfunction still face markedly elevated operative morbidity and mortality rates. Advances in operative technique, myocardial protection, and perioperative critical care have been offset by a steadily increasing risk profile of patients referred for surgical revascularization. In the presence of an LVEF of less than $20 \%$, the requirement for reoperation or urgent operation poses a dramatically increased risk. Attention to myocardial protection, meticulous surgical technique, and perhaps routine preoperative IABP support are required to achieve optimal results in these high-risk patients.

\section{REFERENCES}

1. Christakis GT, Ivanov J, Weisel RD, Birnbaum PL, David TE, Salerno TA. The changing pattern of coronary artery bypass surgery. Circulation 1989;80(Suppl):I151-61.

2. Christakis GT, Weisel RD, Fremes SE, Ivanov J, David TE, Goldman BS, et al. Coronary artery bypass grafting in patients with poor ventricular function. J Thorac Cardiovasc Surg 1992; 103:1083-91.

3. Rao V, Ivanov J, Weisel RD, Ikonomidis JS, Christakis GT, David TE. Predictors of low cardiac output syndrome after coronary artery bypass. J Thorac Cardiovasc Surg 1996;112:38-51.

4. Estefanous FG, Loop FD, Higgins TL, Tekyi-Mensah S, Lytle BW, Cosgrove DM, et al. Increased risk and decreased morbidity of coronary artery bypass grafting between 1986 and 1994. Ann Thorac Surg 1998;65:383-9.

5. Baumgartner FJ, Omari BO, Goldberg S, Pandya AB, Pandya $\mathrm{AB}$, Daland A-M, et al. Coronary artery bypass grafting in patients with profound ventricular dysfunction. Tex Heart Inst J 1998;25:125-9.
6. Elefteriades JA, Morales DL, Gradel C, Tollis G Jr, Levi E, Zaret BL. Results of coronary artery bypass grafting by a single surgeon in patients with left ventricular ejection fractions $\leq 30 \%$. Am J Cardiol 1997;79:1573-8.

7. Mickleborough LL, Maruyama H, Takagi Y, Mohamed S, Sun Z, Ebisuzaki L. Results of revascularization in patients with severe left ventricular dysfunction. Circulation 1995:92(Suppl):II73-9.

8. Hayashida N, Ikonomidis JS, Weisel RD, Shirai T, Ivanov J, Carson SM, et al. The optimal cardioplegic temperature. Ann Thorac Surg 1994;58:961-71.

9. Yau TM, Weisel RD, Mickle DA, Ivanov J, Mohabeer MK, Tumiati L, et al. Optimal delivery of blood cardioplegia. Circulation 1991;84(Suppl 5):III380-8.

10. Yau TM, Ikonomidis JS, Weisel RD, Mickle DA, Ivanov J, Mohabeer MK, et al. Ventricular function after normothermic versus hypothermic cardioplegia. J Thorac Cardiovasc Surg 1993; 105:833-43.

11. Teoh KH, Christakis GT, Weisel RD, Fremes SE, Mickle DA, Romaschin $\mathrm{AD}$, et al. Accelerated myocardial metabolic recovery with terminal warm blood cardioplegia. J Thorac Cardiovasc Surg 1986;91:888-95.

12. Canver CC, Heisey DM, Nichols RD, Cooler SD, Kroncke GM. Long-term survival benefit of internal thoracic artery grafting is negligible in a patient with bad ventricle. J Cardiovasc Surg (Torino) 1998;39:57-63.

13. Anderson WA, Ilkowski DA, Mahan VL, Anolik G, Fernandez J, Laub GW, et al. Coronary artery bypass grafting in patients with chronic congestive heart failure: a 10-year experience with 203 patients. J Card Surg 1997;12:167-75.

14. Dietl CA, Berkheimer MD, Woods EL, Gilbert CL, Pharr WF, Benoit $\mathrm{CH}$. Efficacy and cost-effectiveness of preoperative IABP in patients with ejection fraction of 0.25 or less. Ann Thorac Surg 1996;62:401-9.

15. Christenson JT, Simonet F, Badel P, Schmuziger M. Evaluation of preoperative intra-aortic balloon pump support in high risk coronary patients. Eur J Cardiothorac Surg 1997;11:1097-103.

16. Cimochowski GE, Harostock MD, Foldes PJ. Minimal operative mortality in patients undergoing coronary artery bypass with significant left ventricular dysfunction by maximization of metabolic and mechanical support. J Thorac Cardiovasc Surg 1997;113: 655-66.

17. Sanchez JA, Smith CR, Drusin RE, Reison DS, Malm JR, Rose EA. High-risk reparative surgery: a neglected alternative to heart transplantation. Circulation 1990;82(Suppl 5):IV302-5.

18. Chan RK, Raman J, Lee KJ, Rosalion A, Hicks RJ, Pornvilawan S, et al. Prediction of outcome after revascularization in patients with poor left ventricular function. Ann Thorac Surg 1996;61: 1428-34. 